\title{
Optimalisasi Foto Udara Unmanned Aerial Vehicle (UAV) Sebagai Media Pembelajaran Penginderaan Jauh
}

\author{
Kristhoper Simanungkalit, Muhammad Ridha Damanik, Darwin Parlaungan Lubis \\ Jurusan Pendidikan Geografi, Fakultas Ilmu Sosial, Universitas Negeri Medan \\ JI. Willem Iskandar Pasar V Medan Estate Medan, 20211 Indonesia \\ Email:m.ridha.damanik@gmail.com
}

\begin{abstract}
This study aims (1) To find out how the accuracy of Unmanned Aerial Vehicle (UAV) aerial image quality using the Omission-Commission method. (2) How to use UAV aerial imagery as remote sensing learning media when viewed from the aspects of media feasibility, material worthiness, and student response. This research was conducted at the Medan State University Campus located at Jalan William Iskandar, Pasar V, Medan Estate Village, Medan North Sumatra. This location was chosen based on strategic location considerations for mapping. The results of this study indicate that the quality of the level of precision aerial photographs obtained from aerial photography results in the level of precision aerial photographs reaching above 95\% with excellent categories, and aerial photographs obtained are more inclined towards omission which is influenced by the camera distortion factor, and the feasibility of UAV aerial photography learning media in terms of the aspects of the feasibility of the media achieving an assessment score of $85 \%$, the feasibility aspects of the Material achieving an assessment score of $85 \%$ and, the results of the feasibility of instructional media based on material experts and media experts reach a score level of $85 \%$ and deserve to be used as a medium learning. The results of student responses obtained received an 89\% assessment score, which results from the assessment of student responses that have been said to be good.
\end{abstract}

Keywords: UAV, Remote Sensing, Unimed, Learning Media

\begin{abstract}
Abstrak
Penelitian ini bertujuan (1) Untuk mengetahui bagaimana kualitas akurasi citra foto udara Unmanned Aerial Vehicle (UAV) dengan menggunakan metode Omisi-Komisi. (2) Bagaimana pemanfaatan citra foto udara UAV sebagai media pembelajaran penginderaan jauh bila di lihat dari aspek kelayakan media, kelayakan materi, dan respon mahasiswa. Penelitian ini dilaksanakan di Kampus Universitas Negeri Medan terletak di Jalan William Iskandar, Pasar V, Kelurahan Medan Estate, Medan Sumatera Utara. Lokasi ini dipilih atas pertimbangan lokasi yang strategis untuk melakukan pemetaan. Hasil penelitian ini menunjukkan bahwa Kualitas tingkat presisi foto udara yang didapatkan dari hasil pemotretan foto udara menghasilkan tingkat presisi foto udara mencapai diatas $95 \%$ dengan kategori sangat baik, dan foto udara yang didapatkan lebih condong ke arah omisi yang mana hal ini dipengaruhi oleh faktor distorsi kamera, dan Kelayakan media pembelajaran foto udara UAV ditinjau dari aspek kelayakan Media mencapai skor penilaian 85\%, Aspek kelayakan Materi mencapai skor penilaian $85 \%$ dan, hasil dari kelayakan media pembelajaran berdasarkan ahli materi dan ahli media mencapai tingkat skor $85 \%$ dan layak dijadikan sebagai media pembelajaran. hasil respon mahasiswa yang didapatkan mendapat skor penilaian $89 \%$ yang mana hasil dari penilaian respon mahasiswa sudah dikatakan bagus.
\end{abstract}

Kata Kunci: UAV, Penginderaan Jauh, Unimed, Media Pembelajaran 


\section{PENDAHULUAN}

Pembelajaran adalah sebuah proses komunikasi antara peserta didik dan pengajar, Komunikasi tidak akan berjalan lancar tanpa bantuan sarana penyampaian pesan atau media (Prasetya, 2014). Dalam proses pembelajaran penginderaan jauh terkadang media yang digunakan masih sebatas foto udara yang dari segi temporal terlalu lama dan terkesan kuno, sementara itu pengadaan data foto udara yang neartime digunakan saat ini sulit untuk diperoleh dalam pengadaan foto udara, disamping itu ketergantungan pada data satelit memerlukan biaya yang besar serta masih terkendala oleh tutupan awan (Shofiyanti, 2011).

Penggunaan media pembelajaran dapat mempertinggi proses belajar yang pada gilirannya dapat mempertinggi hasil belajar yang dicapai. Ada beberapa alasan mengapa penggunaan media pembelajaran dapat mempertinggi proses belajar (Sudjana, 2013). Alasan yang berkenaan dengan manfaat media pembelajaran dalam proses pembelajaran, yaitu antara lain (1) media pembelajaran membuat pembelajaran menjadi lebih menarik sehingga menimbulkan motivasi belajar; (2) materi pembelajaran akan lebih jelas maknanya sehingga lebih mudah dipahami dan memungkinkan peserta didik untuk dapat lebih menguasai pembelajaran agar dapat mencapai tujuan pembelajaran lebih baik; (3) metode pembelajaran akan lebih bervariasi sehingga tidak membuat peserta didik bosan; dan (4) peserta didik lebih banyak melakukan kegiatan belajar.

Berdasarkan pra penelitian yang dilakukan melalui wawancara dengan dosen di Fakultas Ilmu Sosial Universitas Negeri Medan mengatakan bahwa pembelajaran penginderaan jauh saat ini digunakan hanya data citra satelit yang mana citra satelit tersebut membutuhkan waktu yang lama untuk pengadaannya, untuk melakukan tugas praktik pengukuran lapangan terbatas dengan citra satelit yang bersifat temporal tersebut, sementara itu, di Universitas Lampung telah memanfaatkan teknologi pesawat udara UAV untuk sebagai bahan materi kuliah mereka, yang mana keunggulan UAV bila diterapkan dalam perkuliahan akan semakin mudah dalam pengadaan data foto udara yang bersifat neartime dan dapat langsing mengolah dan melakukan pengukuran langsung ke lapangan dengan berdasarkan fakta lapangan yang neartime dari wahana UAV.

Perkembangan teknologi khususnya dalam penginderaan jauh yang semakin berkembang pesat dan dengan demikian seharusnya media pembelajaran dapat disesuaikan dengan perkembangan teknologi yang semakin pesat dan dapat digunakan sebagai media pembelajaran yang efektif (Anreza, 2016). Teknologi yang berkembang pesat dalam bidang penginderaan jauh dengan pengambilan data berupa foto (fotogrametri) untuk kepentingan pemetaan yang kini sedang berkembang pesat adalah teknologi Unmanned Aerial Vehicle (UAV) (Haala, Cramer, Weimer, \& Trittler, 2011). Teknologi fotogrametri terus mengalami perkembangan dari masa ke masa, salah satunya adalah pemanfaatan Drone (Dynamic Remotely Operated Navigation Equipment).

Drone merupakan salah satu wahana UAV (Unmanned Aerial Vehicle) yang saat ini sering dijadikan alternatif untuk pengakuisisian data spasial menggantikan wahana pesawat berawak yang relatif mahal. Akan tetapi, untuk kebutuhan informasi yang "near real time" dalam proses pengambilan keputusan. Dimungkinkan untuk bisa mendapatkan data yang mendekati kondisi terkini sehingga bisa mendapatkan hasil yang sesuai dengan fakta lapangan.

Kompetensi yang ingin dicapai dalam penginderaan jauh yaitu antara lain menganalisis dan menginterpretasikan citra hasil pemotretan foto udara, membuat peta, melihat akurasi citra, dan pemanfaatannya untuk berbagai studi. Bila melihat kompetensi yang ingin dicapai tidak cukup hanya dengan lisan, namun membutuhkan media yang foto udara neartime yang dapat memvisualisasikan 
proses perancangan, pengambilan serta pengolahan citra foto udara sesuai dengan materi penginderaan jauh agar mudah dimengerti oleh mahasiswa dan dapat diterapkan dalam proses pembelajaran. Teknologi pemetaan tanpa awak menjadi pilihan alternatif disamping teknologi pemetaan lainnya seperti pemotretan udara baik berawak serta pemetaan berbasis satelit (Wikantika, 2008). Drone sebagai media pembelajaran peginderaan jauh dapat dijadikan sebagai media pembelajaran penginderaan jauh yang efektif, selain mudah di operasikan, mudah di bawa ke lokasi yang sulit terjangkau, dapat dilakukan kapan saja, juga sangat cepat dalam proses pengolahan datanya dan tidak terlalu menggunakan biaya yang besar bila di bandingkan dengan metode pemotretan dengan pesawat berawak ataupun berbasis satelit dan terlebih pemetaan berbasis UAV dapat dilakukan up to date dan pemetaan berbasis UAV dapat di perbarui kapan saja.

Optimalisasi adalah hasil yang dicapai sesuai dengan keinginan, jadi optimalisasi merupakan pencapaian hasil sesuai harapan secara efektif dan efisien (Poerdwadarminta, 1997). Optimalisasi banyak juga diartikan sebagai ukuran dimana semua kebutuhan dapat dipenuhi dari kegiatan- kegiatan yang dilaksanakan.

Dengan melihat kondisi media pembelajaran yang masih sangat terbatas terkhusus dalam pengadaan foto udara yang neartime maka peneliti berinisiatif untuk membuat suatu gebrakan baru dalam membuat suatu media pembelajaran penginderaan jauh berbasis foto udara UAV yang akhir-akhir ini penggunaan UAV marak di masyarakat sehingga dalam pengadaan foto udara yang diperoleh dari
UAV dapat dimanfaatkan menjadi media pembelajaran yang efektif dan efisien guna mencapai tujuan pembelajaran dalam kurikulum materi penginderaan jauh.

Berdasarkan latar belakang diatas, penulis melakukan penelitian dengan judul "Optimalisasi Foto Udara UAV Sebagai Media Pembelajaran Penginderaan Jauh Geografi”.

\section{METODE PENELITIAN}

Penelitian ini berlokasi di Universitas Negeri Medan, Fakultas Ilmu Sosial, Jurusan Pendidikan Geografi Jl. Williem Iskandar Pasar V Medan Estate, Alasan peneliti memilih lokasi penelitian ini karena ingin mengetahui tingkat akurasi foto udara berbasis UAV, selain itu juga ingin mengetahui optimalisasi foto udara UAV sebagai media pembelajaran di Universitas Negeri Medan.

Populasi dalam penelitian ini adalah seluruh Mahasiswa Jurusan Pendidikan Geografi Fakultas IImu Sosial Universitas Negeri Medan NIM 2016 yang berjumlah 137 dan sampel atau responden berjumlah 20,5 mahasiswa (dibulatkan menjadi 20 mahasiswa).

Penelitian yang dilakukan merupakan jenis penelitian dan pengembangan atau Research and Development (R\&D). Metode ini bertujuan untuk menghasilkan produk dan menguji kelayakan produk tersebut. Produk yang dikembangkan adalah media pembelajaran dasar gambar teknik pada mata pelajaran gambar teknik. Prosedur pengembangan media pembelajaran ini menggunakan ADDIE (Analysis, Design, Development and Implementation, Evaluation) (Lee \& Owens, 2004). 


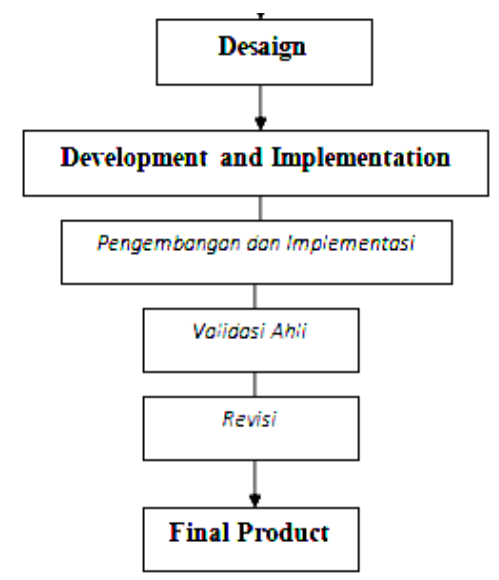

Gambar 1. Diagram Alir Prosedur Pengembangan Metode ADDIE

Adapun teknik pengumpulan data yang digunakan pada penelitian ini meliputi teknik studi dokumenter, interpretasi, observasi, dan teknik komunikasi tidak langsung.

Penelitian ini memiliki instrumen penilaian berupa angket yang digunakan untuk mengevaluasi media pembelajaran yang dikembangkan. Angket ini terbagi dalam dua kategori seperti di bawah ini.

\section{Instrumen Untuk Uji Kelayakan Media} dan Materi.

Pada instrumen ini berisikan tentang poin tentang aspek-aspek yang berhubungan dengan media pembelajaran meliputi :

a) Analisis data angket ahli media dan materi.

Pada pengembangan media pembelajaran penginderaan jauh berbasis UAV uji validitas materi ditunjukkan untuk menguji kelayakan materi yang dikembangkan berdasarkan standar isi, aspek kelayakan penyajian, aspek kelayakan kontekstual sementara itu, uji kelayakan ahli media yang meliputi aspek kelayakan kegrafikan.

Kemudian untuk rumus persentase hasil kelayakan ahli media dan materi dapat dihitung dengan rumus Sugiyono, (2014) sebagai berikut :

$$
\mathrm{P}=\frac{F}{N} x 100 \%
$$

b) Uji Respons Mahasiswa

Pengembangan media pada pembelajaran penginderaan jauh berbasis UAV di uji berdasarkan respon pengguna yang ditunjukkan untuk melihat tanggapan respon mahasiswa yang dikembangkan berdasarkan indikator ketertarikan dan keantusiasan Kemudian untuk rumus persentase hasil respon mahasiswa dapat dihitung dengan perhitungan Sugiono dalam Anreza (2016:3) sebagai berikut :

$$
\text { Respon Mahasiswa }=\frac{\text { Jumlah jawaban ya }}{\text { Jumlah Keseluruhan }} \times 100 \% \ldots
$$

Teknik analisis data yang digunakan dalam penelitian ini adalah teknik analisis deskriptif kualitatif, yaitu dengan mengumpulkan data yang bersifat primer menggunakan wahana UAV sebagai pengumpul data foto udara wilayah Unimed, kemudian setelah data foto udara terkumpul selanjutnya mengolah data foto udara UAV untuk dibuat peta foto udara berbasis UAV kemudian diukur tingkat akurasi foto udara dengan menggunakan rumus omisi. Persamaan metode komisi omisi adalah sebagai berikut (Maulana, 2016):

$$
\text { Akurasi }=\left[1-\left[\frac{\Delta}{\text { Lopongan }}\right]\right] \times 100 \%
$$

dimana $\Delta=$ Interpretasi - Lapangan. 
Setelah mendapatkan tingkat presisi citra foto udara selanjutnya dilihat pemanfaatan media UAV sebagai media pembelajaran penginderaan jauh. Data yang dianalisis dalam penelitian ini yaitu teknik analisis deskriptif kualitatif. Data kualitatif didapat dari kritik dan saran yang diperoleh dari angket uji ahli media, materi dan angket respon mahasiswa. Data tersebut digunakan dalam proses perbaikan dan penyempurnaan media. Data kuantitatif didapat dari skor yang diperoleh dalam angket. Untuk Lembar telaah pemanfaatan media dan materi dapat diukur menggunakan skala Likert dengan skor kelayakan sebagai berikut (Riduwan, 2007):

Tabel 1. Skala Likert Kriteria Kelayakan Ahli.

\begin{tabular}{cc}
\hline Keterangan & Skor \\
\hline Sangat Baik & 5 \\
\hline Baik & 4 \\
\hline Cukup & 3 \\
\hline Kurang & 2 \\
\hline Sangat Kurang & 1 \\
\hline
\end{tabular}

Tabel 2. Skala Likert Kriteria Respon Mahasiswa.

\begin{tabular}{cc}
\hline Keterangan & Skor \\
\hline Tidak & 0 \\
\hline lya & 1 \\
\hline
\end{tabular}

Tabel 3. Kriteria Skor Penilaian Pemanfaatan Media Pembelajaran dan Respon Mahasiswa

\begin{tabular}{cc}
\hline Skor (\%) & Kriteria \\
\hline $0-20$ & Sangat tidak Layak \\
\hline $21-40$ & Tidak Layak \\
\hline $41-60$ & Cukup \\
\hline $61-80$ & Layak \\
\hline $81-100$ & Sangat Layak \\
\hline
\end{tabular}

\section{HASIL DAN PEMBAHASAN}

Hasil penelitian mengenai optimalisasi foto udara UAV sebagai media pembelajaran penginderaan jauh geografi jurusan pendidikan geografi Universitas Negeri Medan terdiri dari dua tahapan, tahapan pertama mengukur tingkat presisi foto udara berdasarkan metode omisikomisi kemudian pemanfaatan UAV sebagai media pembelajaran penginderaan yang di tinjau dari kelayakan ahli media, ahli materi dan respon mahasiswa terhadap media pembelajaran yang digunakan saat proses pembelajaran.

\section{Tingkat Presisi Foto Udara UAV}

Pemotretan dilakukan pada waktu siang hari pukul 12:00 sampai dengan selesai. cakupan area terbang yang dipotret saat penerbangan adalah wilayah kampus Universitas Negeri Medan. Jumlah foto yang dihasilkan 644 foto. Pengambilan foto terkadang memiliki hambatan yang beragam, diantaranya faktor sinyal pancaran WIFI, cuaca, dan lain sebagainya di sekitar Unimed yang dapat mengganggu pengambilan foto udara UAV. Jumlah foto dari hasil pemotretan foto udara UAV yang di dapat berjumlah 644 foto udara, kemudian hasil data foto udara yang 
berjumlah 644 foto udara selanjutnya di lakukan pembuatan citra foto udara UAV.
Penentuan titik sampel dapat dilihat pada Tabel 4.

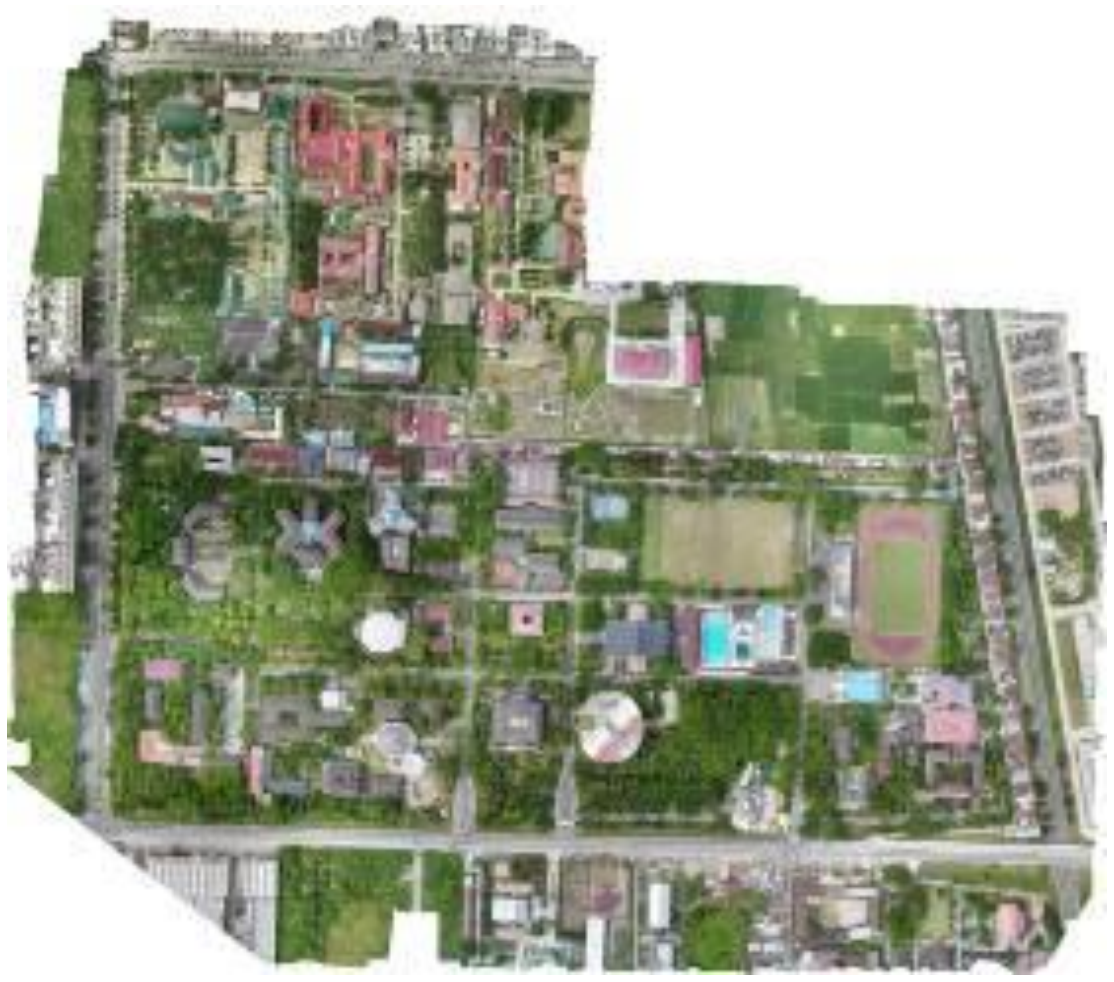

Gambar 2. Foto Udara UAV Wilayah Unimed.

Tabel 4. Tabel Survey Lapangan

\begin{tabular}{|c|c|c|c|c|c|}
\hline \multirow[b]{2}{*}{ No } & \multicolumn{2}{|c|}{ Kordinat } & \multirow{2}{*}{ Interpretasi } & \multirow{2}{*}{$\begin{array}{l}\text { Objek di } \\
\text { Lapangan }\end{array}$} & \multirow{2}{*}{ Ketepatan } \\
\hline & $x$ & $\bar{Y}$ & & & \\
\hline 1 & $98^{\circ} 43^{\prime} 8,106 ” E$ & $3^{\circ} 36^{\prime} 28,67^{\prime \prime} \mathrm{N}$ & $\begin{array}{l}\text { Kolam Renang } \\
\text { Umum Unimed }\end{array}$ & $\begin{array}{l}\text { Kolam Renang } \\
\text { Umum Unimed }\end{array}$ & $\checkmark$ \\
\hline 2 & $\begin{array}{c}98^{\circ} \\
42^{\prime} 52,211 \text { ”E }\end{array}$ & $\begin{array}{c}3^{\circ} 36^{\prime} \\
35,48^{\prime \prime} \mathrm{N}\end{array}$ & $\begin{array}{c}\text { Tepi Jalan } \\
\text { Pameran Seni/Lab } \\
\text { Teknik }\end{array}$ & $\begin{array}{c}\text { Tepi Jalan } \\
\text { Pameran } \\
\text { Seni/Lab Teknik }\end{array}$ & $\checkmark$ \\
\hline 3 & $98^{\circ} 43^{\prime} 9,269^{\prime \prime} \mathrm{E}$ & $3^{\circ} 36^{\prime} 29,394^{\prime \prime} \mathrm{N}$ & $\begin{array}{l}\text { Kolam Lompat } \\
\text { Indah }\end{array}$ & $\begin{array}{l}\text { Kolam Lompat } \\
\text { Indah }\end{array}$ & $\checkmark$ \\
\hline 4 & $98^{\circ} 43^{\prime} 9,496^{\prime \prime} \mathrm{E}$ & $3^{\circ} 36^{\prime} 29,09 ” \mathrm{~N}$ & $\begin{array}{l}\text { Kolam Lompat } \\
\text { Indah }\end{array}$ & $\begin{array}{c}\text { Kolam Lompat } \\
\text { Indah }\end{array}$ & $\checkmark$ \\
\hline 5 & $98^{\circ} 43^{\prime} 3,206^{\prime \prime} \mathrm{E}$ & $3^{\circ} 36^{\prime} 32,778^{\prime \prime} \mathrm{N}$ & $\begin{array}{c}\text { Lebar Lapangan } \\
\text { Voly }\end{array}$ & $\begin{array}{c}\text { Lebar Lapangan } \\
\text { Voly }\end{array}$ & $\checkmark$ \\
\hline 6 & $98^{\circ} 43^{\prime} 3,042^{\prime \prime} \mathrm{E}$ & $3^{\circ} 36^{\prime} 32,489^{\prime \prime} \mathrm{N}$ & $\begin{array}{c}\text { Panjang Lapangan } \\
\text { Voly }\end{array}$ & $\begin{array}{c}\text { Panjang } \\
\text { Lapangan Voly }\end{array}$ & $\checkmark$ \\
\hline 7 & $98^{\circ} 43^{\prime} 8,106^{\prime \prime} \mathrm{E}$ & $3^{\circ} 36^{\prime} 31,911^{\prime} \mathrm{N}$ & $\begin{array}{l}\text { Panjang Garis } \\
\text { Parkiran FIS }\end{array}$ & $\begin{array}{l}\text { Panjang Garis } \\
\text { Parkiran FIS }\end{array}$ & $\checkmark$ \\
\hline
\end{tabular}


Foto udara yang telah diolah menjadi citra foto udara UAV yang telah diolah tersebut ditentukan sampel secara acak dengan titik sampel sebanyak 7 titik. Titik sampel tersebut adalah 1) lebar kolam umum, 2) lebar tepi jalan pameran seni, 3) lebar kolam lompat indah, 4) panjang kolam lompat indah, 5) lebar lapangan voli, 6) panjang lapangan voli, 7) panjang parkiran garis parkiran FIS. kemudian dibandingkan jarak antara hasil interpretasi dengan lapangan dengan menggunakan metode Omisi-Komisi. Hasil pengukuran dapat dilihat pada tabel berikut.

Tabel 5. Pengukuran Objek Interpretasi dan lapangan

\begin{tabular}{|c|c|c|c|c|c|c|}
\hline \multirow{2}{*}{ No } & \multirow{2}{*}{ Nama Objek } & \multicolumn{2}{|c|}{ Kordinat } & \multicolumn{2}{|c|}{ Panjang Pengukuran } & \multirow{2}{*}{ Selisih } \\
\hline & & $x$ & $\mathrm{Y}$ & Interpretasi & Lapangan & \\
\hline 1 & Lebar Kolam Umum & $98^{\circ} 43^{\prime} 8,106^{\prime \prime E}$ & $3^{\circ} 36^{\prime} 28,67 ” \mathrm{~N}$ & 25,14 & 25,10 & 0,04 \\
\hline 2 & $\begin{array}{l}\text { Lebar Tepi Jalan } \\
\text { Pameran Seni/Lab Teknik }\end{array}$ & $98^{\circ} 42 ’ 52,211$ ”E & $3^{\circ} 36^{\prime} 35,48^{\prime \prime} \mathrm{N}$ & 4,44 & 4,38 & 0,06 \\
\hline 3 & $\begin{array}{l}\text { Lebar Kolam Lompat } \\
\text { Indah }\end{array}$ & $98^{\circ} 43^{\prime} 9,269^{\prime \prime} \mathrm{E}$ & $3^{\circ} 36^{\prime} 29,394 ” N$ & 15,80 & 15,88 & 0,08 \\
\hline 4 & $\begin{array}{l}\text { Panjang Kolam Lompat } \\
\text { Indah }\end{array}$ & $98^{\circ} 43^{\prime} 9,496^{\prime \prime E}$ & $3^{\circ} 36^{\prime} 29,09 ” N$ & 16,90 & 17,00 & 0,10 \\
\hline 5 & Lebar Lapangan Voly & $98^{\circ} 43^{\prime} 3,206^{\prime \prime E}$ & $3^{\circ} 36^{\prime} 32,778 ” N$ & 9,04 & 9,00 & 0,04 \\
\hline 6 & Panjang Lapangan Voly & $98^{\circ} 43^{\prime} 3,042 ” E$ & $3^{\circ} 36^{\prime} 32,489^{\prime \prime} \mathrm{N}$ & 17,93 & 17,98 & 0,05 \\
\hline 7 & $\begin{array}{l}\text { Panjang Garis Parkiran } \\
\text { FIS }\end{array}$ & $98^{\circ} 43^{\prime} 8,106^{\prime \prime E}$ & $3^{\circ} 36^{\prime} 31,911^{\prime} \mathrm{N}$ & 3,87 & 3,90 & 0,03 \\
\hline
\end{tabular}

Berdasarkan hasil pengukuran yang telah dilakukan, baik itu pengukuran langsung di lapangan maupun di laboratorium, kemudian dilakukan perhitungan dengan menggunakan metode Omisi-Komisi untuk menentukan tingkat presisi. Berikut adalah salah satu contoh perhitungan pada objek berupa "Lebar Tepi Jalan Pameran Seni/Lab Teknik”.

$$
\text { Presisi }=\left[1-\left[\frac{\Delta}{\text { Lapangan }}\right]\right] \times 100 \%
$$

Presisi $=\left[1-\left[\frac{4,44-4,38}{4,38}\right]\right] \times 100 \%$

Presisi $=[1-0,01369863] \times 100 \%$

Presisi $=0,98630137 \times 100 \%$

Presisi $=98 \%$

Dengan Menggunakan metode yang sama dilakukan perhitungan pada objek hasil pengukuran lainya, maka didapatkan persentase presisi objek pada sampel lainya. Persentase Hasil Perhitungan uji presisi dapat diamati pada Tabel 6. 
Tabel 6. Tingkat Presisi Foto Udara UAV

\begin{tabular}{llrrr}
\hline \multirow{2}{*}{ No } & \multicolumn{1}{c}{ Objek Pengukuran } & \multicolumn{2}{c}{ Panjang Pengukuran } & \multicolumn{2}{c}{$\begin{array}{c}\text { Presisi } \\
\text { Interpretasi }\end{array}$} \\
\cline { 3 - 4 } 1 & Lebar Kolam Umum & 25,14 & 25,10 & $99 \%$ \\
\hline 2 & Panjang Kolam Umum & 49,80 & 49,92 & $99 \%$ \\
\hline 3 & $\begin{array}{l}\text { Lebar Tepi Jalan Pameran Seni/Lab } \\
\text { teknik }\end{array}$ & 4,44 & 4,38 & $98 \%$ \\
\hline 4 & Lebar Kolam Lompat Indah & 15,80 & 15,98 & $98 \%$ \\
\hline 5 & Panjang Kolam Lompat Indah & 16,90 & 17,00 & $98 \%$ \\
\hline 6 & Lebar Lapangan Voli & 9,04 & 9,00 & $99 \%$ \\
\hline 7 & Panjang Lapangan Voli & 17,93 & 17,98 & $98 \%$ \\
\hline 8 & Panjang Garis Parkiran FIS & 3,87 & 3,90 & $99 \%$ \\
\hline & & & Sumber: Hasil Analisis, 2018
\end{tabular}

Hasil perhitungan dengan metode OmisiKomisi didapatkan persentase pengujian presisi objek. Dari kedelapan objek persentase presisi berada diatas $98 \%$. hal tersebut menunjukkan bahwa data UAV sangat terlihat bagus pada citra foto udara, Nilai piksel terlihat berkualitas baik dan tidak melihat efek distorsi. Untuk lebih jelasnya dapat dilihat pada gambar berikut.

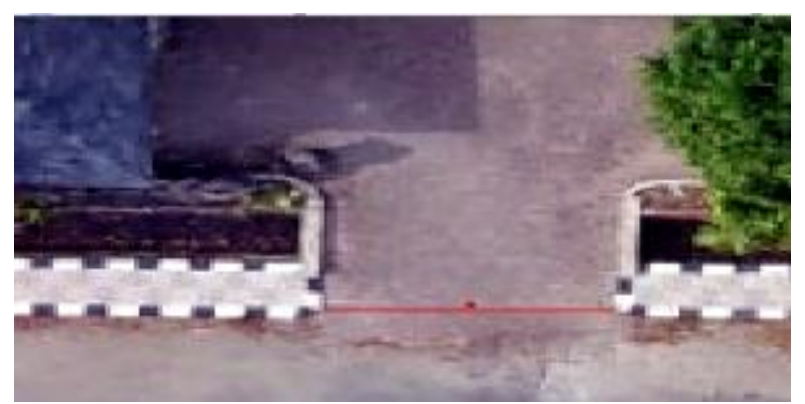

Gambar 3. Lebar Tepi Jalan Pameran Seni/Lab Teknik 98 42'52,211' $E$ dan 3'36'35,48' N

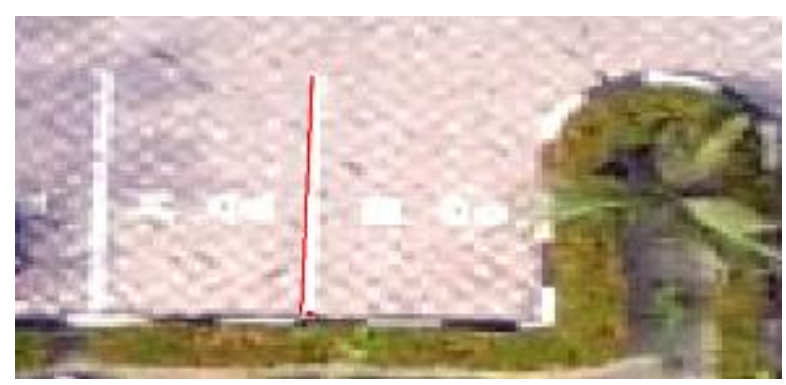

Gambar 4. Panjang Garis Parkiran FIS 98³'8,106"'E dan $3^{\circ} 36^{\prime} 31,911^{\prime} \mathrm{N}$ 


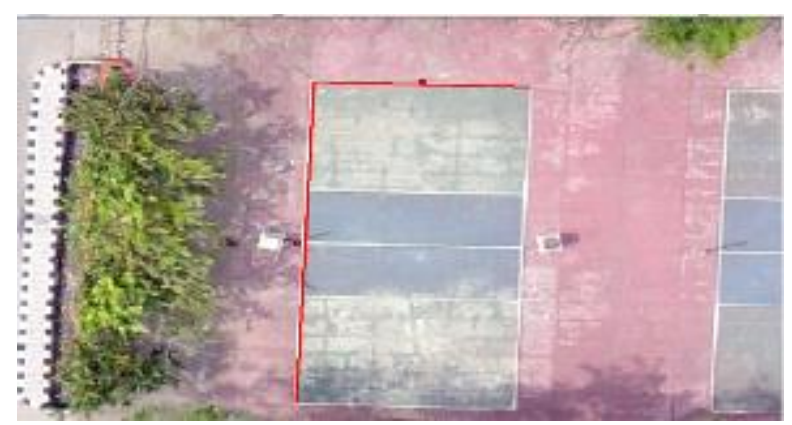

Gambar 5. Lapangan Voli (Panjang) 98'43'3,042"E dan 3'36’32,489"N, (Lebar) $98^{\circ} 43^{\prime} 3,206^{\prime \prime} E$ dan $3^{\circ} 36^{\prime} 32,778^{\prime \prime} \mathrm{N}$

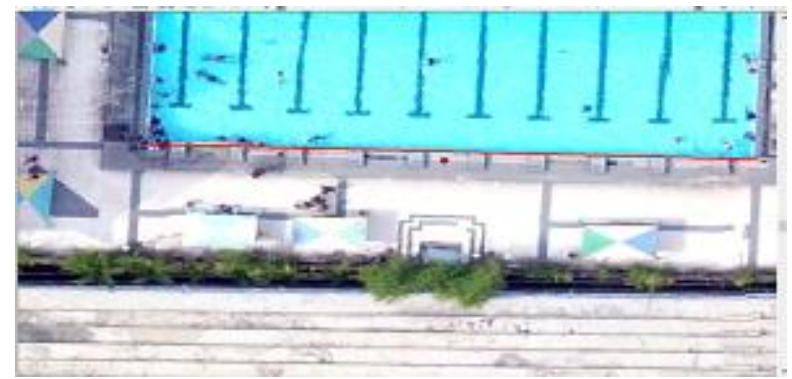

Gambar 6. Lebar Kolam Umum 98 $43^{\prime} 8,106^{\prime \prime}$ E dan 3³6'28,67”N

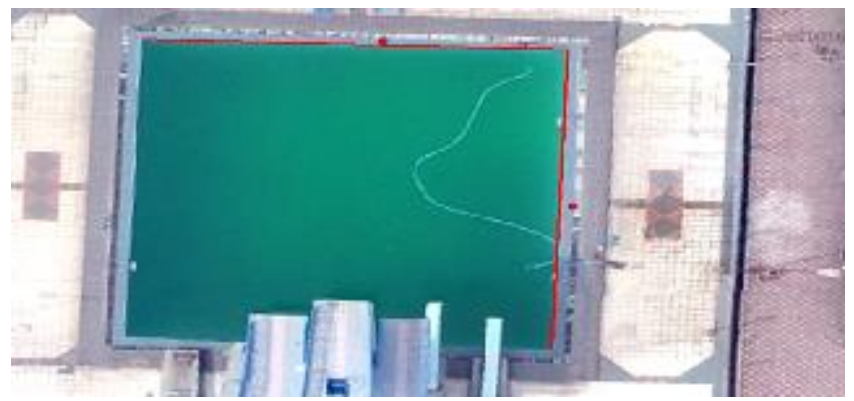

Gambar 7. Kolam Lompat Indah (Panjang) 9843'9,496"E dan 3'36'29,09"N, (Lebar) 98'43'9,269" E dan 3'36'29,394”N

Sementara itu tingkat resolusi citra foto udara UAV wilayah UNIMED menggunakan software mission planner yang bila mengikuti algoritmanya adalah CSD $=7,27 \mathrm{~cm} /$ piksel. yang mana dengan nilai ukur sebenarnya $(\mathrm{cm})$ yang dihitung dalam bentuk $\mathrm{cm} /$ piksel $7,27 \mathrm{~cm} /$ piksel berarti 1 piksel pada citra $=7,27 \mathrm{~cm}$ pada ukuran sebenarnya).

Dari kualitas 7 sampel presisi omisikomisi, sampel pertama terjadi nilai komisi atau lebih panjang dari hasil lapangan sebesar $0.04 \mathrm{~cm}$, sampel ke dua terjadi nilai komisi atau lebih panjang dari hasil lapangan sebesar $0.06 \mathrm{~cm}$. sampel ke tiga terjadi nilai omisi atau lebih kecil dari hasil lapangan sebesar $0.08 \mathrm{~cm}$, sampel ke empat terjadi nilai omisi atau lebih kecil dari hasil lapangan sebesar $0.10 \mathrm{~cm}$, sampel ke lima terjadi nilai komisi atau lebih panjang dari hasil lapangan sebesar $0.04 \mathrm{~cm}$, sampel ke enam terjadi nilai omisi atau lebih kecil dari hasil lapangan sebesar $0.05 \mathrm{~cm}$, sampel ke tujuh terjadi nilai omisi atau lebih kecil dari hasil lapangan sebesar $0.04 \mathrm{~cm}$. Dari hasil penilaian ke seluruh sampel omisi dan komisi terjadi efek omisi dari sampel 3,4,6,7 dan efek komisi terjadi pada sampel 1,2, dan 5. hal ini terjadi karna terjadi efek distorsi atau pembiasan yang terjadi oleh 
kamera. Hasil citra foto udara UAV sudah sangat bagus dalam kualitas citra foto udara dan tingkat kualitas citra foto udara sudah dapat melebihi dari citra satelit.

\section{Kelayakan Media Pembelajaran Geografi}

Pada penelitian dan pengembangan ini menghasilkan modul pembelajaran berupa modul perancangan dan pengoperasian media pembelajaran Penginderaan Jauh berbasis foto udara UAV yang telah divalidasi, diujicobakan dan dilakukan perbaikan. Produk final dari modul pembelajaran ini terdiri dari 3 bab yang disertai dengan latihan-latihan untuk setiap babnya serta memiliki jumlah halaman sebanyak 58 halaman dan A4 dengan 4 Standard kompetensi penginderaan jauh yang terdiri atas mengkaji konsep PJ, membuat peta citra foto udara, menghitung ketelitian, serta memahami konsep multi dalam penginderaan jauh.

\section{Tahap Analisis}

Analisis merupakan tahap awal yang harus dilakukan karena pada tahap ini permasalahan-permasalahan yang ditemukan dalam proses perkuliahan media pembelajaran fisika dikaji kemudian dirumuskan cara pemecahan masalahnya. Tahap analisis kebutuhan dilakukan melalui wawancara didapati bahwa selama ini penggunaan media foto udara yang digunakan masih tetap yang lama tanpa ada pembaharuan data foto udara kemudian masih banyak mahasiswa yang mengalami kesulitan dalam mengukur tingkat akurasi foto udara yang dikarenakan foto udara yang digunakan sudah sangat lama, sehingga dalam pengukuran secara lapangan tidak dapat maksimal. sementara itu foto udara yang digunakan mahasiswa selama ini belum mampu dalam membantu mahasiswa untuk mengkreasikan perancangan foto udara keterampilan mereka secara mandiri. Maka dari itu peneliti mengembangkan media foto udara berbasis foto udara UAV agar mahasiswa mampu memahami kompetensi yang ingin di capai. Berikut adalah tahapan analisis: a) Analisis Kurikulum

Kurikulum yang dipilih dalam pengembangan media ini adalah PJ, membuat peta citra foto udara, menghitung ketelitian, serta memahami konsep multi dalam penginderaan jauh

b) Analisis Media

Media yang dikembangkan adalah modul foto udara berbasis UAV yang fleksibel dan dapat di bawa kemana saja.

c) Analisis Materi

Materi yang dikembangkan disesuaikan lagi dengan indikator yang di capai diantaranya.

- Menjelaskan definisi konsep dasar, perkembangan PJ dan unsur - unsur interpretasi foto udara.

- Mampu memahami perencanaan terbang foto udara, pengambilan data foto udara, pengolahan data foto udara menjadi DEM dan Orthopoto.

- Memahami cara menentukan titik sampel, melakukan pengukuran omisi-komisi.

- Memanfaatkan citra fotografi untuk berbagai studi

\section{Tahap Desain}

Tahap selanjutnya dalam prosedur pengembangan adalah tahap desain. Tahap desain ini meliputi penyusunan standar kompetensi, pembuatan sampul media, penyusunan materi, pemberian soal-soal latihan.

3. Tahap pengembangan atau development.

a) Penilaian ahli materi dan media tahap satu.

Tahap pertama ini adalah tahap dimana pengujian berdasarkan ahli media, ahli materi. Didapati bahwa ahli materi mendapatkan nilai 87, ahli media mendapat nilai 50. Maka dalam penilaiannya adalah:

$$
\text { Ahli Materi }=\frac{87}{130} \times 100 \%=66 \%
$$




$$
\text { Ahli Media }=\frac{50}{65} \times 100 \%=76 \%
$$

Maka berdasarkan skor penilaian ahli materi $66 \%$ dan ahli media mendapatkan nilai $76 \%$ maka pengembangan media oleh ahli media dan materi yang dikembangkan masih perlu perbaikan.

b) Penilaian ahli materi dan media tahap dua.

Tahap ke dua ini adalah tahap dimana pengujian perbaikan pada media pembelajaran berdasarkan ahli media, ahli materi. Didapati bahwa ahli materi mendapatkan nilai 111, ahli media mendapat nilai 55. Maka dalam penilaiannya adalah:

$$
\begin{aligned}
\text { Ahli Materi } & =\frac{111}{130} \times 100 \%=85 \% \\
\text { Ahli Media } & =\frac{55}{65} \times 100 \%=85 \%
\end{aligned}
$$

Maka didapatkan kelayakan media tiap aspek adalah

$$
\text { Ahli Materi }=\frac{85+85}{2} \times 100 \%=85 \%
$$

Berdasarkan kriteria skor penilaian ahli media mendapatkan nilai $85 \%$ dan materi mendapatkan nilai $85 \%$ dan didapatkan hasil kelayakan media dari hasil materi dan media mencapai tingkat $85 \%$ dan sudah dikatakan layak maka dengan demikian media yang dikembangkan sudah valid dan layak untuk diujicobakan pada mahasiswa.
Dari tabel hasil penilaian ahli materi pada tahap ke dua mendapatkan total nilai dengan nilai 111 dan perhitungan rumus (Sugiyono, 2014) maka penilaian dari ahli materi mendapatkan skor penilaian $85 \%$ dengan kategori penilaian layak dan tidak perlu revisi.

\section{c) Respon Mahasiswa}

Penilaian angket respon mahasiswa adalah tahap dimana untuk melihat tanggapan respon mahasiswa. Didapati bahwa total nilai yang didapat dari respon mahasiswa mendapatkan nilai 178 , dan berdasarkan skor penilaian skala Guttman respon mahasiswa mendapat nilai $89 \%$. Maka dalam penilaiannya adalah:

$$
\text { Respon Mahasiswa }=\frac{178}{200} \times 100 \%=89 \%
$$

Dari tabel hasil penilaian responden mahasiswa mendapatkan total nilai dengan nilai 178 dan penilaian berdasarkan rumus (Sugiyono, 2014), maka penilaian dari responden mahasiswa mendapatkan skor penilaian $89 \%$ dengan kategori penilaian sangat baik.

\section{PEMBAHASAN}

\section{Presisi Foto Udara UAV}

Dengan Menggunakan metode yang sama dilakukan perhitungan pada objek hasil pengukuran lainya, maka didapatkan persentase presisi objek pada sampel lainya. Persentase Hasil Perhitungan uji presisi dapat diamati sebagai berikut Presisi perbandingan Laboratorium dan Lapangan

Tabel 7. Analisis Foto Udara UAV, 2018

\begin{tabular}{llrrr}
\hline \multirow{2}{*}{ No } & \multirow{2}{*}{ Objek Pengukuran } & \multicolumn{2}{c}{ Panjang Pengukuran } & \multirow{2}{*}{ Presisi } \\
\cline { 3 - 4 } & Labolatorium & Lapangan & Interpretasi \\
\hline 1 & Lebar Kolam Umum & 25,14 & 25,10 & $99 \%$ \\
\hline 2 & Lebar Tepi Jalan Pameran Seni/Lab teknik & 4,44 & 4,38 & $98 \%$ \\
\hline 3 & Lebar Kolam Lompat Indah & 15,80 & 15,98 & $98 \%$ \\
\hline 4 & Panjang Kolam Lompat Indah & 16,90 & 17,00 & $98 \%$ \\
\hline 5 & Lebar Lapangan Voli & 9,04 & 9,00 & $99 \%$ \\
\hline 6 & Panjang Lapangan Voli & 17,93 & 17,98 & $98 \%$ \\
\hline 7 & Panjang Garis Parkiran FIS & 3,87 & 3,90 & $99 \%$ \\
\hline & & & Sumber: Hasil Analisis, 2018
\end{tabular}


Hasil perhitungan dengan metode Omisi-Komisi didapatkan persentase pengujian presisi objek. Dari kedelapan objek persentase presisi berada diatas $95 \%$. hal tersebut menunjukkan bahwa data UAV sangat terlihat bagus pada citra foto udara, Nilai piksel terlihat berkualitas baik dan tidak melihat efek distorsi.

\section{Kelayakan Media Pembelajaran}

Ditinjau dari aspek Kelayakan kegrafikan dari ahli media yaitu sebesar $85 \%$. Sementara itu untuk aspek kelayakan isi, penyajian, dan kontekstual dari ahli materi yaitu memperoleh nilai rata-rata $85 \%$, sehingga dapat disimpulkan bahwa media pembelajaran penginderaan jauh berbasis foto udara UAV interaktif pada mata pelajaran Penginderaan Jauh dikategorikan layak untuk digunakan. Hasil uji validasi oleh ahli materi berupa hasil tanggapan dan penilaian dari ahli materi, kemudian dari hasil data yang diperoleh dianalisis dan dilakukan revisi produk sesuai dari saran. sehingga dapat disimpulkan bahwa media pembelajaran interaktif pada mata pelajaran Penginderaan Jauh dikategorikan layak untuk digunakan.

Penilaian respon mahasiswa setelah tahap perbaikan dan revisi produk media foto udara UAV yang dijadikan sebagai media pembelajaran penginderaan jauh mencapai presentasi $89 \%$ dan berdasarkan angka penilaian maka tingkat respon mahasiswa terhadap media foto udara UAV yang dikembangkan dilihat dari presentasi penilaian mahasiswa sangan tertarik terhadap pengembangan media foto udara UAV.

\section{KESIMPULAN DAN SARAN}

Berdasarkan rumusan masalah dalam penelitian ini, maka dapat dikemukakan beberapa kesimpulan sebagai berikut:

1. Kualitas tingkat presisi foto udara yang didapatkan dari hasil pemotretan foto udara yang dilakukan pada waktu siang hari pukul 12:00 sampai dengan selesai. dengan luas cakupan area terbang yang dipotret saat penerbangan adalah 16 hektar dengan tingkat presisi foto udara mencapai diatas 95\% dengan kategori sangat baik, dan foto udara yang didapatkan lebih condong ke arah omisi yang mana hal ini dipengaruhi oleh faktor distorsi kamera. dan dari hasil citra foto udara UAV sudah sangat bagus dalam kualitas citra foto udara dan tingkat kualitas citra foto udara sudah dapat melebihi dari citra satelit.

2. Kelayakan media pembelajaran foto udara UAV ditinjau dari aspek kelayakan Media mencapai skor penilaian $85 \%$, Materi mencapai skor penilaian $85 \%$ dan, hasil dari kalkulasi kelayakan media berdasarkan ahli materi dan media dari ke dua skor penilaian ahli media mencapai tingkat skor $85 \%$ dan layak dijadikan sebagai media pembelajaran., hasil respon siswa yang didapatkan mendapat skor penilaian $89 \%$ yang mana hasil dari penilaian respon mahasiswa sudah dikatakan bagus.

Adapun hal;-hal yang dapat disarankan dari hasil penelitian ini adalah:

1. Kamera yang digunakan dalam pengambilan foto udara omisi komisi sebaiknya terus di kembangkan, agar hasil citra foto udara lebih sedikit mengalami efek distorsi.

2. Perlu dikembangkan lagi penggunaan UAV untuk dijadikan fasilitator kepada mahasiswa guna mencapai tujuan pembelajaran yang ingin di capai terkhusus dalam materi penginderaan jauh.

3. Bagi pihak kampus sebaiknya lebih memperhatikan perkembangan teknologi terkhusus dalam fotogrametri, dikarenakan sudah banyak pihak universitas lain sudah memanfaatkan teknologi UAV sebagai bahan materi perkuliahan mereka.

4. Untuk peneliti lain yang ingin lebih memahami atau mendalami teknologi foto udara UAV untuk mampu mengembangkan terkait pengaruh 
kestabilan terbang terhadap kualitas foto udara yang diinginkan.

\section{DAFTAR PUSTAKA}

Anreza, P. M. (2016). Pengembangan Media Pembelajaran Syma Quadcopter Camera Pada Materi Penginderaan Jauh Untuk Tata Guna Lahan Dan Transportasi Bagi Siswa Kelas XII di SMA Negeri 16 Surabaya. Swara Bhumi, 3(3).

Haala, N., Cramer, M., Weimer, F., \& Trittler, M. (2011). Performance test on UAV-based photogrammetric data collection. International Archives of the Photogrammetry, Remote Sensing and Spatial Information Sciences, 38(6).

Lee, W. W., \& Owens, D. L. (2004). Multimedia-based instructional design: computer-based training, web-based training, distance broadcast training, performance-based solutions. John Wiley \& Sons.

Maulana, E. (2016). UJI AKURASI DATA UAV (UNMANNED AERIAL VEHICLE) DI KAWASAN PANTAI PELANGI, PARANGTRITIS, KRETEK, KABUPATEN
BANTUL. In Science-Technology Base Marine and Fisheries Development for Sustainability.

Poerdwadarminta, W. J. S. (1997). Kamus Besar Bahasa Indonesia. Balai Pustaka, Jakarta.

Prasetya, S. P. (2014). Media Pembelajaran Geografi. Yogyakarta: Ombak.

Riduwan, M. B. A. (2007). Skala pengukuran variabel-variabel penelitian. Alf. Bandung.

Shofiyanti, R. (2011). Teknologi pesawat tanpa awak untuk pemetaan dan pemantauan tanaman dan lahan pertanian. Informatika Pertanian, 20(2), 58-64.

Sudjana, N. (2013). Dasar-dasar Proses Belajar Mengajar (Cetakan ke-13). Bandung: Sinar Baru Algesindo.

Sugiyono. (2014). Metode Penelitian Kuantitatif Kualitatif dan $R \& D$. Bandung: Alfabeta.

Wikantika, K. (2008). Unmanned Mapping Technology: Development and Applications. In Proceeding Workshop UnMapTech2008. 
available at http://jurnal.unimed.ac.id/2012/index.php/tgeo

Jurnal Tunas Geografi

e-ISSN: 2622-9528 p-ISSN: 2301-606X

Vol. 08 No. $01-2019$ 